\title{
BMJ Open Vitality, resilience and the need for support among hospital employees during the COVID-19 pandemic: study protocol of a mixed-methods study
}

\author{
Margo van Mol (D) , ${ }^{1}$ Mathijs de Veer, ${ }^{2}$ Anne de Pagter, ${ }^{3}$ \\ T A Kouwenhoven-Pasmooij, ${ }^{4}$ Witte J G Hoogendijk, ${ }^{5}$ Jan J van Busschbach, ${ }^{2}$ \\ Karen Oude Hengel, ${ }^{6}$ Leonieke Kranenburg ${ }^{2}$
}

To cite: van Mol M, de Veer M, de Pagter A, et al. Vitality, resilience and the need for support among hospital employees during the COVID-19 pandemic: study protocol of a mixedmethods study. BMJ Open 2021;11:e049090. doi:10.1136/ bmjopen-2021-049090

- Prepublication history for this paper is available online. To view these files, please visit the journal online (http://dx.doi. org/10.1136/bmjopen-2021049090).

Received 16 January 2021 Accepted 27 September 2021

Check for updates

(C) Author(s) (or their employer(s)) 2021. Re-use permitted under CC BY-NC. No commercial re-use. See rights and permissions. Published by BMJ.

For numbered affiliations see end of article.

Correspondence to

Dr Margo van Mol;

m.vanmol@erasmusmc.nl

\section{ABSTRACT}

Introduction The COVID-19 pandemic has had a significant impact on the physical and mental functioning of healthcare professionals, especially those working on the 'frontline', and other hospital workers. At the onset of the crisis, various interventions were introduced to promote resilience and offer mental support to these professionals. However, it is unknown whether the interventions will meet the needs of professionals as the COVID-19 pandemic continues.

The goal of this exploratory study is to gain insight in factors that protect the vitality and resilience of Dutch hospital employees during the so-called 'second wave' of the COVID-19 pandemic. This paper describes the study protocol.

Methods and analysis This exploratory study applies a mixed-methods design, using both quantitative and qualitative methods of data collection and analysis. The first part of the study (substudy I) consists of surveys among doctors and nurses in COVID-19 departments and non-COVID-19 departments, and other professionals in the hospital (ie, managers and homeworkers) in 2020 and 2021. The second part of the study (substudy II) consists of focus groups and interviews among professionals of the intensive care unit, COVID-19 departments and infection prevention units.

Ethics and dissemination The research protocol for this study has been approved by the Medical Ethics Committee (MEC-2020-0705). The outcomes of this study will be used to develop and implement interventions to support hospital employees maintaining their vitality and resilience during and after the COVID-19 pandemic. Employees with vitality experience less work-related stress and make a positive contribution to healthcare quality.

\section{INTRODUCTION}

Worldwide, it has been reported that the COVID-19 pandemic had a significant impact on the physical and mental functioning of healthcare professionals, especially for those working on the 'frontline' (eg, intensive care units (ICUs), COVID-19 departments and infection prevention units). ${ }^{1-4}$ Indeed, also
Strengths and limitations of this study

- A mixed-methods design will be applied which strengthens the insights on vitality, resilience and the need for support among hospital employees.

- Insight in vitality, resilience and need for support of frontline workers from different departments will be investigated, as well as managers and homeworkers who will be compared in contrast to the majority of studies so far, which focused mainly on the needs of healthcare professionals such as nurses and doctors.

- Real-life data gathering started during the beginning of second COVID-19 wave, ongoing to autumn 2021.

- The COVID-19 pandemic is the motivation for this study, but may also limit the response rates or generalisability of this study, given its unpredictable course.

in the Netherlands, the COVID-19 pandemic had an impact on healthcare workers. This is critical, as it has been reported that some Dutch medical professionals were already overburdened before the pandemic. ${ }^{56}$

The need for high-intensity medical treatment of patients rapidly increased during the COVID-19 pandemic, during which the work circumstances became uncertain and stressful. ${ }^{7}$ These work circumstances included the continuous use of personal protective equipment, adapted responsibilities and tasks, moral dilemmas and the risk of contamination for the healthcare professionals themselves. ${ }^{8}$ Interpersonal contact with patients' family members, one of the core features of the professional practice of nurses, was considerably reduced due to visiting limitations in most hospitals. ${ }^{9}{ }^{10} \mathrm{In}$ addition, the work environment also changed for ICU nurses as their teams changed due to the practical help from (former) colleagues 
and other healthcare professionals. This sudden shift in activities and responsibilities required ICU nurses to have additional competences maintaining high-quality healthcare. Buddies, or support staff from other departments in the hospital, were sometimes confronted with distressing or even shocking events during the first hectic weeks of the pandemic. Professionals of the infection prevention unit had to deal with an enormous workload due to the accumulation of new tasks and changing work processes, as well as the social turbulence resulting from the implemented quarantine measures. In the case of a health crisis such as the COVID-19 pandemic, the health and vitality of the frontline professionals became even more critical. Because a higher workload and stress could have a higher appeal on the physical and mental resources of the professionals. However, the COVID-19 pandemic not only had impact on the clinicians of the hospital, but the work environment also changed for non-clinical professionals who suddenly had to work and communicate from home. In addition to this, homeworkers might lack a sense of purpose, solidarity and valuable contribution to the crisis situation. ${ }^{11}$ Last, the COVID-19 pandemic required great effort from managers. ${ }^{12}$ More than ever, they had to deal with logistic and administrative processes in the upscaling of high-intensity care, improving work alliances and the integration of staff in newly formed teams, and in managing the continuous flow of changing information.

\section{Health, vitality and resilience}

In previous virus outbreaks, such as the outbreaks of Severe Acute Respiratory Syndrome (SARS), Ebola and Middle East Respiratory syndrome (MERS), it became clear that increased stress levels at work in healthcare professionals were associated with fear of contamination; shortages of materials; poor communication between healthcare professionals; unclear work instructions and information; deficient or non-functioning equipment; and inadequate planning among healthcare professionals. ${ }^{13-16}$ Experiences from China during the COVID-19 pandemic showed similar results. ${ }^{17-19}$ In a European study on work-related stress reactions among ICU healthcare professionals, half $(50.4 \%)$ of the respondents showed symptoms of anxiety after the first wave of COVID-19. ${ }^{1}$ Early phase evidence on COVID-19 suggested that healthcare professionals experienced mood and sleep disturbances during the outbreaks, stressing the need to establish ways to minimise mental health risks and support interventions aiming at pandemic conditions. ${ }^{3}$ In the short-term, this work-related stress can cause fatigue, sleep disorders, mistakes and moral distress. ${ }^{20}$ Long-term effects of high work pressure include burnout, depression and post-traumatic stress, resulting in dropout due to illness and abandonment of paid employment. ${ }^{21} 22 \mathrm{~A}$ recent Dutch study among intensivists reported a moderate risk for burnout $(14.8 \%){ }^{23}$ Furthermore, recovery time-regaining strength after an intensive period at work-has been associated with physical and mental well-being, ${ }^{24}$ as a long recovery time is an early indicator of work-related stress and exhaustion. ${ }^{25}$ In contrast to high workload, stress and less recovery time, vitality, resilience and job satisfaction were described as characteristics of professionals that counterbalance workrelated stress. ${ }^{26} 27$ These characteristics could strengthen professionals' mental and physical well-being and their retention for work. ${ }^{28-30}$ Therefore, professionals with a high level of vitality and resilience seemed more resistant to work pressure.

\section{Interventions among healthcare professionals during the COVID-19 pandemic}

A wide variety of studies have examined interventions to reduce the work-related stress of healthcare professionals during the COVID-19 pandemic. Providing personal protective equipment is the top priority, followed by fulfilling the psychological needs of professionals. ${ }^{31}$ To support mental health and promote the vitality of healthcare professionals, various interventions, including buddy systems, peer support, coaching and easily accessible psychological help, were proposed during the first months of COVID-19 wave. ${ }^{732-36}$ Other individual interventions, such as telemedicine activities, e-package and self-help books, appeared promising. ${ }^{37-40}$ For example, a hospital in China offered online courses to help medical professionals to deal with psychological problems. ${ }^{41}$ Many interventions have taken an individual approach, but system-level changes in healthcare organisations seemed to have a wider reach than individual support. ${ }^{42}$ A notable omission in the literature is that protective factors were given limited attention: the focus is on the stressors. Many possible interventions were likely to support professionals in times of a pandemic, however, it is not clear which intervention matches the needs of the professional most closely. Therefore, a study was set-up to investigate which supportive interventions, system changes and other supportive factors could meet individual needs during and in the aftermath of the COVID-19 pandemic in a large academic hospital in the Netherlands.

\section{Objectives}

The overall goal of the explorative study is to gain insight into the risk and protective factors as well as the needs and barriers in the working environment related to the promotion of the vitality and resilience of employees. Our objective is to assess levels of vitality and resilience, and the need for support or resources among professionals with a focus on professionals working in ICUs, COVID-19 departments, homeworkers and infection prevention units. Furthermore, to gain more insight into the relationship of vitality and resilience with factors such as self-perceived health, stress, burnout, post-traumatic stress and need for recovery. The aim of the current paper is to describe the protocol of this explanatory mixed-methods study.

\section{METHODS AND ANALYSIS \\ Study design}

A mixed-methods design, using both quantitative (substudy I) and qualitative methods (substudy II), is 
applied. Substudy I is a cross-sectional online survey administered first in October 2020, when the second wave of the COVID-19 pandemic was upcoming and ongoing, followed with measurements in March and September 2021. Substudy II includes focus group interviews among nurses, doctors and professionals regarding the ICU, COVID-19 departments and the infection prevention unit during the end of 2020 .

\section{Setting}

The study setting is a large academic hospital in the Netherlands.

\section{Study population \\ Substudy I}

The population consists of a random sample drawn based on voluntary participation of four target groups: professionals working at the COVID-19 department, nonCOVID-19 departments, managers and homeworkers. A convenience sample has been used to monitor the health of the hospital workers, as was also done in comparable studies performed during the COVID-19 pandemic. ${ }^{43} 44$ We estimated the sample size of the consecutive quantitative measurements as $25 \%$ of the healthcare workers in the four target groups. Several organisational strategies will be followed to stimulate participation and reach the threshold of the aimed response rates.

\section{Substudy II}

The population for the focus groups are the frontline workers. Maximum variation sampling is used, with respect to the type of frontline departments (ICU, COVID-19 departments, infection prevention unit) and occupational groups (physicians, nurses and infection prevention experts), resulting in six focus groups.

The inclusion criteria for the entire study are (1) a minimum age of 18 years and (2) sufficient Dutch language proficiency to complete the questionnaires or to discuss the relevant topic.

\section{Patient and public involvement \\ No patient involved.}

\section{Study procedures}

\section{Substudy I: Oonline survey}

Hospital employees are informed about the study in several ways. The communication strategy is tailored to each target group and supported by the communication department of the organisation. A link to the online survey is published on the intranet of the organisation, printed QR-codes containing a link to the survey are available at the coffee corners and canteens, announcements are made in the weekly COVID-19 livestream and by team management via personal email. Participation is voluntary and can be performed during working hours.

The online questionnaire starts with information about the study, privacy statements and an informed consent form for participation. After providing consent, participants are asked to fill out the entire questionnaire, which consists of two parts. The first part is generic for all employees and takes approximately 6 min to complete; it includes questions on demographic information and the main outcomes. The second part consists of additional modules on working conditions and health and takes approximately $7 \mathrm{~min}$. Nurses and homeworkers receive an additional module tailored to their specific work environment.

\section{Substudy II: focus groups}

In total, six focus groups with 6-10 participants that take approximately $60 \mathrm{~min}$ are conducted. ICU doctors, ICU nurses, microbiologists, hospital hygienists, COVID-19 unit nurses and COVID-19 unit doctors (lung specialists and specialists internal medicine) are individually invited to participate in one of the focus groups through consultation with the team managers. These meetings are preferably in-person (to observe non-verbal attitude and facial expressions), but due to the COVID-19 measures and social distancing, it may not be possible for participants to be physically present. In those cases, the focus groups are carried out via video calling technology.

Prior to the meetings, a topic list is created by the research group based on the literature and internal reports on the experiences of professionals. This topic list is used to guide and structure the meeting. The aim of the focus group is to study protective factors that contribute to vitality and resilience during the COVID-19 pandemic. Furthermore, possible interventions to increase vitality and resilience are explored and elaborated on. Written informed consent is given prior to the meeting, and two experienced researchers guide the meetings. The focus group interviews are recorded and transcribed verbatim.

\section{Measurements}

This paragraph lists all measurement instruments included in the questionnaire. The first part consists of measuring instruments addressing demographics, primary outcomes (ie, vitality, resilience and needs assessment) and several secondary outcomes (ie, self-perceived health, stress, burnout, post-traumatic stress and need for recovery). The second part consists of separate modules for homeworkers and nurses with regard to work ability, working conditions, job satisfaction, work-private balance, exposure to COVID-19 at work, preventive measures for COVID-19 and career perspectives.

\section{Demographics}

Gender, age, educational level, job titles, work location and professionals' experience (in years) are assessed. Educational level is divided into three levels: low, medium and high educational level. In total, the list of job titles includes 23 positions within the academic hospital (eg, nurse, Information Technology (IT) specialist employee, pharmacist, educator, researcher). 
Main outcome measures

\section{Vitality}

Vitality is measured with four items from the original 36-item Short Form Health Survey. ${ }^{45}$ The total summed score of four items that refer to the past 4 weeks: 'Did you feel full of liveliness?', 'Did you have a lot of energy?', 'Did you feel worn out?' and 'Did you feel tired?'. The answers are rated on a six-point scale from 1 (=constantly) to 6 (=never). ${ }^{46}$ Higher scores indicating a better subjective vitality.

\section{Resilience}

Resilience (the ability to cope with stress, setbacks or difficulties at work) is measured with six items from the Psychological Capital Questionnaire. ${ }^{47}$ The items contain statements such as: 'When I have a setback at work, I have a hard time getting back on track and moving on', 'If necessary, I can work well without the help of others' and 'I can handle difficult moments at work'. The six items are scored from 1 (=strong disagreement) to 6 (=strong agreement). Higher values indicate a higher level of resilience.

\section{Needs assessment}

Needs are measured with a self-designed scale with four items. Examples of questions are: 'In which area would you like to be supported?' and 'What would this support look like?' and 'What should be offered or developed?'. A predefined list includes 10 individual-related and 14 organisational-related answer options, for example, support for working from home, time management and work-private balance.

\section{Other outcome measures}

\section{Self-perceived health}

Self-rated health is assessed with one question: 'In general, how would you say your health is?' Answer options from 1 (=excellent) to 5 (=poor).

\section{Stress}

Stress is measured with a numeric rating scale. The stress score, ranging from 0 (=no stress at all) to 100 (=the worst stress imaginable). This scale is used to retrospectively objectify stress before, during and after the first COVID-19 outbreaks. The three item question was 'How did you experience the stress before/during/after the COVID-19 crisis on a scale from 0 to 10 ?'

\section{Burnout}

Burnout is measured using five items, that are based on an adapted version of the Utrecht Burnout Scale. ${ }^{48}$ The items refer to the current situation such as 'I feel emotionally drained from my job' and 'I feel completely exhausted from my work'. The answer options from 1 (=never) to 7 (=daily).

\section{Post-traumatic stress}

Post-traumatic stress is assessed with the post-traumatic stress disorder (PTSD) Checklist for the Diagnostic and
Statistical Manual of Mental Disorders (DSM- version V) (PCL-5)-COVID-19 version with 20 items. ${ }^{49}$ This scale consists of 20 items, measuring PTSD symptoms, with scoring options from 0 (=not all) to 4 (=extremely) and was adapted to the COVID-19 situation. A score of 33 or higher is perceived indicative for PTSD.

\section{Need for recovery}

Work fatigue and the risk of psychological symptoms are measured using the Dutch questionnaire on the Experience and Evaluation of Work (Dutch abbreviation: VBBA). ${ }^{50} 51$ The need for recovery scale consists of 11 dichotomous items (yes/no), representing short-term effects of a working day. ${ }^{2452} 53$ The score of the need for recovery scale ranges from 0 to 100 and is calculated as the sum of points $(1=$ yes, $0=$ no) divided by the number of questions answered, multiplied by 100 . Higher scores indicate a higher need for recovery, which is unfavourable.

\section{Work ability}

Work ability is measured with the Work Ability Index (WAI). ${ }^{54}$ This widely used index measures self-assessed work ability and consists of seven items. Because the subitems of the WAI can also be used as a simple indicator for work ability, ${ }^{55}$ three of the seven items are used: current work ability (one item), and work ability in relation to physical and mental job demands (two items). A total WAI score (range: 2-20) is obtained by adding the weight scores of these individual items. ${ }^{56}$

\section{Working conditions}

Aspects of work load in the current study are: job autonomy, emotional job demands, social support and physical working conditions.

Job autonomy is measured with six items on a three point scale (no; yes, sometimes; yes, regularly). Five items, that is, those about making decisions, having to find solutions and being able to take time off, are based on the Job Content Questionnaire. ${ }^{57} 58$ One item on autonomy related to working time based on the Netherlands Working Conditions Survey, is also included in the questionnaire. $^{59}$

Emotional job demands are evaluated with four items. Three items are derived from the Copenhagen Psychosocial Questionnaire and assess whether the work leads to emotionally difficult situations, the emotional demands of the job and emotional involvement in work. An additional item is 'Is your job more emotionally demanding because of COVID-19?'. All items are measured on a fourpoint scale (never to always). ${ }^{60}$

Social support is defined as whether colleagues and supervisors are willing to help and listen to workrelated problems and is assessed using four items from COPSOQ. ${ }^{60}$ Social support is measured on four-point Likert scales from 1 (=almost never) to 5 (=always).

Physical work loads are measured with one selfdesigned question and assess whether a worker received more or less physically demanding work due to COVID-19 
measures. This scale has three answer options (no; yes, sometimes; yes, regularly).

\section{Job satisfaction}

Job satisfaction is measured with one item: 'Altogether, how satisfied are you with your work?' The answer options range from 1 (very dissatisfied) to 5 (very satisfied).

\section{Work-private life balance}

Work-private life balance is measured with two questions on the mutual interference between work and home life. The questions are adopted from the Netherlands Working Conditions Survey ${ }^{59}$ but were originally constructed by Fox and Dwyer (1999) ${ }^{61}$ Both questions have four answer options ranging from 1 (=no, never) to 4 (=very often).

\section{Exposure to COVID-19 at work}

Professionals are asked to what extent they might have been exposed to COVID-19 at the worksite. These questions are derived from the Netherlands Working Conditions Survey COVID-19, ${ }^{62}$ based on questionnaires developed within the OMEGA network. ${ }^{63}$ Participants are asked if they work with patients, the average number of patients they work with during a typical working day in the last week, and if these patients are suspected to have or had been diagnosed with COVID-19. Additionally, participants are asked if and with how many workers they work on a regular basis with colleagues, and if they share tools or surfaces with their colleagues.

\section{Preventive measures for COVID-19}

The five questions on preventive measures with regard to COVID-19 are derived from the Netherlands Working Conditions Survey COVID-19. ${ }^{62}$ One general question assesses the general measures taken at the department level with regard to the COVID-19 pandemic, with answer options such as homeworking, adjustment of working hours, general preventive measures in the workplace, mandatory inclusion or withdrawal of leave. The specific questions on preventive measures include the possibility of keeping a $1.5 \mathrm{~m}$ distance between colleagues and/or patients, the availability of personal protective equipment, the usage of personal protective equipment and the application of general hygiene measures. The responses to these five questions are never, sometimes, often and always. This module will not be applied to homeworkers.

\section{Career perspective}

Three items on career perspective are derived from the Netherlands Working Conditions Survey COVID-19 ${ }^{62}$ and adjusted to fit the study population working in the hospital. These items include the motivation to work in the healthcare sector in the future (responses: less, equal and more), the intention to change jobs within the healthcare sector and the intention to change jobs outside the healthcare sector with responses ranging from 1 (=certainly not) to 5 (=certainly yes).
Outcome measures for pre-defined groups or professions Nurse questionnaire

The Practice Environment Scale of the Nursing Work Index is the most widely used measure to gauge the state of nursing practice environments. ${ }^{6465}$ It is the only measure recommended by several organisations promoting quality healthcare. The 15-item questionnaire uses responses ranging from 1 (=strongly disagree) to 4 (=totally agree). This module will be applied to nurses only.

\section{Homeworkers}

A total of eight items are specifically tailored to homeworkers. Two items refer to the number of hours in a week people work from home and how many hours a day they work on a screen (eg, laptop and tablet). One item is focused on the availability of ergonomic work equipment at home (a desk or table with a comfortable working height, a chair that can be adjusted to one's body measurements, a separate display and a separate computer mouse). The need for other furniture is assessed with one item 'Do you need additional materials for a good home workplace?'. Moreover, participants are asked if they take (short) breaks on a working day, except for a lunch break?'. This question includes the following answer options: 1 (=yes, regularly), 2 (=yes, sometimes) and $3(=$ no). The last three items are about concentration while at home and include the following statements: 'Do you have trouble concentrating while working?', 'Do you struggle to keep your attention while you work?' and 'Do you have difficulty with the reduced social contact with colleagues?' Answer options range from 1 (=never) to 4 (=always).

\section{Data handling and statistical analyses \\ Sub study I}

Survey data are anonymously collected using Limesurvey (V.2.06 lts Build 160524) and exported to a secure SPSS database (IBM SPSS Statistics for Windows, V.25.0. Armonk, New York: IBM Corp) for analysis. All principal investigators have access to the final study dataset. Data will be stored for 15 years.

First, the data are cleaned and checked for missing data. The descriptive statistics are presented as numbers and percentages for dichotomous variables and mean and SD for continuous variables. Data for different subgroups (professionals in COVID-19 departments, non-COVID-19 departments, managers and homeworkers) are analysed with the Mann-Whitney test or t-tests. Linear and logistics regression analyses are preformed to investigate the associations between risk factors and the main outcomes (vitality and resilience). Statistical significance will be defined as $\mathrm{p}<0.05$.

\section{Sub study II}

Focus groups data will be analysed by means of thematic content analysis. ${ }^{66}$ This method organises and describes the dataset in rich detail and investigates patterns of response or meaning within the dataset. We take an 
inductive approach to identify possible themes. Once a satisfactory thematic map is established, the themes are examined to identify the 'essence' of what each individual theme is about and to understand how they are interrelated in relation to our research question. To achieve this, the following steps will be taken.

Focus group interview data are audiotaped and transcribed verbatim. ${ }^{66}$ Two researchers will read the transcripts in detail. Each of them starts with developing a structured analysis framework that consists of preliminary codes and themes. They make use of mind maps and tables to organise the data. After that, they compare their frameworks to reach consensus. Next, one researcher codes the transcripts line by line according to this framework in the software programme NVivo V.12. The coder uses memos for comments during coding. When coding is finished and the code 'other' is used, the two researchers discuss these codes and rename them into a new or existing code name best reflecting the contents of the otherwise uncategorised text fragment. During and after coding, the two researchers review and check the themes for internal homogeneity and external heterogeneity. Finally, the two researchers analyse the cohesion and inter-relations between themes to come to a coherent account and accompanying narrative of the data. The principal investigators have access to these data, which will be stored for 15 years.

\section{ETHICS AND DISSEMINATION}

The study is approved by the Medical Ethics Committee of the Erasmus MC (MEC-2020-0705). It will be conducted according to the principles of the Declaration of Helsinki (64th WMA General Assembly, Fortaleza, Brazil, October 2013) and in accordance with the Medical Research Involving Human Subjects Act. The study complies with the Netherlands Code of Conduct for Scientific Practice from the Association of Universities in the Netherlands. Protocol modifications will be communicated and to the Medical Ethics Committee by protocol amendment. Participants will be informed about the study both orally and by letter. Consent for participation will be given by written informed consent. Participants can leave the study at any time for any reason if they wish to do so without any consequences. The withdrawal will be registered for informative purpose.

\section{DISCUSSION}

The consequences of the COVID-19 crisis on the mental health and working conditions of healthcare professionals have been recognised worldwide. ${ }^{67}$ Hospital employees with vitality experience less work-related stress and can therefore handle more work in the new and stressful circumstance. In other words, maintaining professionals' vitality and resilience will contribution to healthcare quality. By using a mixed-methods approach, we aim to gain an overview of vitality, resilience and health (eg, stress and burnout) among healthcare professionals, as well as the risk factors associated with these outcomes. The COVID-19 pandemic has put an extra focus on the impact of work-related stress and how to deal with its causes and consequences. Even though the pandemic entails a specific surge of specific patients, and as such may hamper generalisability, we believe that the outcomes of this study will add to the body of knowledge on how best to deal with the work-related stress experienced by healthcare workers worldwide.

This is an urgent and rushed study because we wanted to use the results against the same health crisis that we are investigating. Based on this study, directions for future interventions during the COVID-19 pandemic and thereafter could provide raised levels of vitality and resilience of professionals in the hospital, and therewith support their employability in the long run.

\section{Strengths and limitations}

The first strength is the mixed-methods design, consisting of qualitative and quantitative methods which provide a more in-depth insight in the need for support in the exploratory study and therewith details the information to develop interventions. Second, we compare different departments and distinguish healthcare workers, managers, and homeworkers. The majority of studies so far focused exclusively on the needs of healthcare professionals without considering other hospital employees such as supportive staff, researchers and managers.

The COVID-19 pandemic was the motivation for this research, but may also have limited the procedure of this study, given its unpredictable course. During the writing of this protocol paper, the second wave of COVID-19 had already started in the Netherlands. Therefore, a lower response rate is not unexpected from the frontline healthcare workers. The second limitation is the cross-sectional design of the study, which makes it impossible to draw causal conclusions from this report and to investigate the lont-term effects.

\section{Data dissemination}

Public access to the study protocol, study details, participant-level dataset and statistical code can be acquired from the corresponding author. The results will be disseminated to healthcare professionals, health services authorities and the public via presentations at national and international meetings and published in peer-reviewed journals. A lay summary of the results will be written and shared with all professionals of the organisation.

\section{Study status}

The study is currently ongoing with data recruitment.

\section{Author affiliations}

${ }^{1}$ Intensive Care Adults, Erasmus Medical Center, Rotterdam, Zuid-Holland, The Netherlands

${ }^{2}$ Department of Psychiatry, Section Medical Psychology, Erasmus Medical Center, Rotterdam, The Netherlands 
${ }^{3}$ Department of Pediatrics, Erasmus Medical Center, Rotterdam, The Netherlands ${ }^{4}$ Department of Occupational Health, Erasmus Medical Center, Rotterdam, The Netherlands

${ }^{5}$ Department of Psychiatry, Erasmus Medical Center, Rotterdam, The Netherlands ${ }^{6}$ Netherlands Organization for Applied Scrientific Research TNO, Leiden, The Netherlands

Acknowledgements The authors would like to thank all participating respondents for their involvement in the study.

Contributors MVM, TAK-P, JJVB and LK jointly designed the study, raised funding and established the development of the study protocol. MVM, MdV, TAK-P, KOH and LK prepared the study materials. MVM, MdV and LK gathered the data of both substudies and produced the first draft of the article outline together with $\mathrm{KOH}$ and TAK-P. All authors (MVM, MdV, AdP, TAK-P, JJVB, WJGH, KOH and LK) contributed substantially to the concept of the study, the analyses of literature, critically revised the content of the manuscript, have read and approved the final version.

Funding This work was internally supported by the board of Erasmus MC (no grant number applicable).

Competing interests None declared.

Patient and public involvement Patients and/or the public were not involved in the design, or conduct, or reporting or dissemination plans of this research.

Patient consent for publication Not applicable.

Provenance and peer review Not commissioned; externally peer reviewed.

Open access This is an open access article distributed in accordance with the Creative Commons Attribution Non Commercial (CC BY-NC 4.0) license, which permits others to distribute, remix, adapt, build upon this work non-commercially, and license their derivative works on different terms, provided the original work is properly cited, appropriate credit is given, any changes made indicated, and the use is non-commercial. See: http://creativecommons.org/licenses/by-nc/4.0/.

\section{ORCID iD}

Margo van Mol http://orcid.org/0000-0002-0213-6054

\section{REFERENCES}

1 Azoulay E, De Waele J, Ferrer R, et al. Symptoms of burnout in intensive care unit specialists facing the COVID-19 outbreak. Ann Intensive Care 2020;10:1-8.

2 Kok N, Hoedemaekers A, van der Hoeven $\mathrm{H}$, et al. Recognizing and supporting morally injured ICU professionals during the COVID-19 pandemic. Intensive Care Med 2020;46:1653-4.

3 Pappa S, Ntella V, Giannakas T, et al. Prevalence of depression, anxiety, and insomnia among healthcare workers during the COVID-19 pandemic: a systematic review and meta-analysis. Brain Behav Immun 2020;88:901-7.

4 Lai J, Ma S, Wang Y, et al. Factors associated with mental health outcomes among health care workers exposed to coronavirus disease 2019. JAMA Netw Open 2020;3:e203976.

5 Solms L, van Vianen AEM, Theeboom T, et al. Keep the fire burning: a survey study on the role of personal resources for work engagement and burnout in medical residents and specialists in the Netherlands. BMJ Open 2019;9:e031053.

6 Prins JT, Hoekstra-Weebers JEHM, van de Wiel HBM, et al. Burnout among Dutch medical residents. Int J Behav Med 2007;14:119-25.

7 Rieckert A, Schuit E, Bleijenberg N, et al. How can we build and maintain the resilience of our health care professionals during COVID-19? recommendations based on a scoping review. BM Open 2021;11:e043718.

8 Gold JA. Covid-19: adverse mental health outcomes for healthcare workers. Brit Med J Publish Group 2020;369:m1815.

9 Bagnasco A, Zanini M, Hayter M, et al. COVID 19-A message from Italy to the global nursing community. JAN 2020.

10 Murthy S, Gomersall CD, Fowler RA. Care for critically ill patients with COVID-19. JAMA 2020;323:1499-500.

11 Joly $\mathrm{H}$. Lead your team into a post-pandemic world. Harvard Business Review 2020;8.

12 Kniffin KM, Narayanan J, Anseel F, et al. COVID-19 and the workplace: implications, issues, and insights for future research and action. Am Psychol 2021;76:63-77.

13 Maunder R, Hunter J, Vincent L, et al. The immediate psychological and occupational impact of the 2003 SARS outbreak in a teaching hospital. CMAJ 2003;168:1245-51.
14 Ulrich CM. Ebola is causing moral distress among African healthcare workers. BMJ 2014;349:g6672.

15 Wu P, Fang Y, Guan Z, et al. The psychological impact of the SARS epidemic on hospital employees in China: exposure, risk perception, and altruistic acceptance of risk. Can J Psychiatry 2009;54:302-11.

16 Bukhari EE, Temsah MH, Aleyadhy AA, et al. Middle East respiratory syndrome coronavirus (MERS-CoV) outbreak perceptions of risk and stress evaluation in nurses. J Infect Dev Ctries 2016;10:845-50.

17 Zhu Z, Xu S, Wang H. COVID-19 in Wuhan: immediate psychological impact on 5062 health workers. MedRxiv2020.

18 Xiao H, Zhang Y, Kong D, et al. The effects of social support on sleep quality of medical staff treating patients with coronavirus disease 2019 (COVID-19) in January and February 2020 in China. Med Sci Monit 2020;26:923549-1.

19 Zhang Y, Wang C, Pan W, et al. Stress, burnout, and coping strategies of frontline nurses during the COVID-19 epidemic in Wuhan and Shanghai, China. Front Psychiatry 2020;11:1154.

20 De Villers MJ, DeVon HA. Moral distress and avoidance behavior in nurses working in critical care and noncritical care units. Nurs Ethics 2013;20:589-603.

21 Moss M, Good VS, Gozal D, et al. An official critical care societies collaborative statement: Burnout syndrome in critical care health care professionals: a call for action. Am J Crit Care 2016;25:368-76

22 van Mol MMC, Kompanje EJO, Benoit DD, et al. The prevalence of compassion fatigue and burnout among healthcare professionals in intensive care units: a systematic review. PLoS One 2015;10:e0136955

23 Meynaar IA, Ottens T, Zegers M, et al. Burnout, resilience and work engagement among Dutch intensivists in the aftermath of the COVID-19 crisis: a nationwide survey. J Crit Care 2021;62:1-5.

24 Graham B, Cottey L, Smith JE, et al. Measuring 'Need for Recovery' as an indicator of staff well-being in the emergency department: a survey study. Emerg Med J 2020;37:555-61.

25 Nieuwenhuijsen K, Sluiter JK, Dewa CS. Need for recovery as an early sign of depression risk in a working population. Int J Occup Environ Med 2016;58:e350-4.

26 van Mol MMC, Nijkamp MD, Bakker J, et al. Counterbalancing work-related stress? work engagement among intensive care professionals. Aust Crit Care 2018;31:234-41.

27 Schaufeli WB, Salanova M, González-romá V, et al. The measurement of engagement and burnout: a two sample confirmatory factor analytic approach. J Happiness Stud 2002;3:71-92.

28 Schaufeli WB. Engaging leadership in the job demands-resources model. Career Development International 2015;20:446-63.

29 Bakker AB, Demerouti E, Sanz-Vergel AI. Burnout and work engagement: the JD-R approach. Annu. Rev. Organ. Psychol. Organ. Behav. 2014;1:389-411.

30 Yu F, Raphael D, Mackay L, et al. Personal and work-related factors associated with nurse resilience: a systematic review. Int J Nurs Stud 2019;93:129-40.

31 Santarone K, McKenney M, Elkbuli A. Preserving mental health and resilience in frontline healthcare workers during COVID-19. Am J Emerg Med 2020;38:1530-1.

32 Ministerie van Defensie. Tips \& adviezen voor de mentale gezondheid van zorgprofessionals. Retrieved from. Available: https://www. waardigheidentrots.nl/wp-content/uploads/2020/03/Flyer-MentaleGezondheid-zorgprofessionals-tijdens-corona.pdf

$33 \mathrm{Hu}$ Y-Y, Fix ML, Hevelone ND, et al. Physicians' needs in coping with emotional stressors: the case for peer support. Arch Surg 2012;147:212-7

34 Albott CS, Wozniak JR, McGlinch BP. Battle Buddies: rapid deployment of a psychological resilience intervention for health care workers during the coronavirus disease 2019 pandemic. Anesth Anal 2020.

35 Leszcz M, Maunder R, Hunter J. Psychological support for health care workers during the COVID-19 pandemic. CMAJ 2020;192:E660.

36 Kisely S, Warren N, McMahon L, et al. Occurrence, prevention, and management of the psychological effects of emerging virus outbreaks on healthcare workers: rapid review and meta-analysis. BMJ 2020;369:m1642.

37 Jing $\mathrm{H}$, Fangkun L, Ziwei T, et al. Care for the psychological status of frontline medical staff fighting against COVID-19. Clin Infect Dis 2020;71.

38 Percudani M, Corradin M, Moreno M. Mental health services in Lombardy during COVID-19 outbreak. Psychiatry Res 2020;112980.

39 Kang L, Ma S, Chen M, et al. Impact on mental health and perceptions of psychological care among medical and nursing staff in Wuhan during the 2019 novel coronavirus disease outbreak: a cross-sectional study. Brain Behav Immun 2020;87:11-17. 
40 Blake H, Bermingham F, Johnson G, et al. Mitigating the psychological impact of COVID-19 on healthcare workers: a digital learning package. Int J Environ Res Public Health 2020;17:2997.

41 Chen Q, Liang M, Li Y, et al. Mental health care for medical staff in China during the COVID-19 outbreak. Lancet Psychiatry 2020;7:e15-16.

42 Wu PE, Styra R, Gold WL. Mitigating the psychological effects of COVID-19 on health care workers. CMAJ 2020;192:E459-60.

43 Heesakkers $\mathrm{H}$, Zegers $\mathrm{M}$, van Mol MMC, et al. The impact of the first COVID-19 surge on the mental well-being of ICU nurses: a nationwide survey study. Intensive Crit Care Nurs 2021;65:103034.

44 Cag Y, Erdem H, Gormez A, et al. Anxiety among front-line healthcare workers supporting patients with COVID-19: a global survey. Gen Hosp Psychiatry 2021;68:90-6.

45 Ware JE, Sherbourne CD. The mos 36-item short-form health survey (SF-36). I. conceptual framework and item selection. Med Care 1992;30:473-83.

46 van der Zee KI, Sanderman R. Measuring health status with the RAND-36. A manual. [Het meten van de gezondheidstoestand met de RAND-36. Een handleiding], Groningen, 1993.

47 Luthans F, Avolio BJ, Avey JB, et al. Positive psychological capital: measurement and relationship with performance and satisfaction. Pers Psychol 2007;60:541-72.

48 Schaufeli WB, Dierendonck DV. Utrecht Burnout Scale [Utrechtse Burnout Schaal] (UBOS). De psycholoog 2001;6:9-12.

49 Weathers FW, Litz BT, Keane TM. The PTSD checklist for DSM-5 (pcl-5). scale available from the National center for PTSD. Available: https://www.ptsd.va.gov/professional/assessment/adult-sr/ptsdchecklist.asp

50 Broersen JPJ, Fortuin RJ, Dijkstra L. Health and Safety Covenants Monitor: key figures and limit values [Monitor Arboconvenanten: kengetallen en grenswaarden]. TBV-Tijdschrift voor Bedrijfs-en Verzekeringsgeneeskunde 2004;12:104-8.

51 Mv V, Meijman MT. Measuring psychosocial workload with a questionnaire: the questionnaire perception and assessment of work [Het meten van psychosociale arbeidsbelasting met een vragenlijst: de vragenlijst beleving en beoordeling van de arbeid. Nederlands Instituut voor Arbeidsomstandigheden, 1994

52 Jansen NWH, Kant IJ, van den Brandt PA. Need for recovery in the working population: description and associations with fatigue and psychological distress. Int J Behav Med 2002;9:322-40.

53 Moriguchi CS, Trevizani T, de Fátima Carreira Moreira R, et al. Need for recovery assessment among nursing professionals and call center operators. Work 2012;41 Suppl 1:4838-42.
54 IImarinen J. Ageing workers in Finland and in the European Union: their situation and the promotion of their working ability, Employability and employment. Issues and Practice 1999;26:623-41.

55 Ahlstrom L, Grimby-Ekman A, Hagberg M, et al. The work ability index and single-item question: associations with sick leave, symptoms, and health - a prospective study of women on long-term sick leave. Scand J Work Environ Health 2010;36:404-12.

56 Tuomi K, Ilmarinen J, Jahkola A. Work ability index. Helsinki: Finnish Institute of occupational health; 1998. Occup Health Care 1998;19.

57 Karasek R. Job Content Questionnaire user's guide. Department of Work Environemnt, 1985.

58 Karasek R, Brisson C, Kawakami N, et al. The job content questionnaire (JCQ): an instrument for internationally comparative assessments of psychosocial job characteristics. J Occup Health Psychol 1998;3:322-55

59 Hooftman WE, Mars GMJ, Knops JCM, et al. National Working Conditions Survey 2019. Methodology and global results [Nationale Enquête Arbeidsomstandigheden 2019. Methodologie en globale resultaten. TNO; CBS, 2020.

60 Kristensen TS, Borg V. Copenhagen psychosocial questionnaire (COPSOQ). Mental Health 2003:5:5

61 Fox ML, Dwyer DJ. An investigation of the effects of time and involvement in the relationship between stressors and work-family conflict. J Occup Health Psychol 1999;4:164-74.

62 Bouwens L, Zoomer T, Hooftman W, et al. Reading guide National Working Conditions Survey - COVID-19 [Leeswijzer Nationale Enquête Arbeidsomstandigheden - COVID-19. Leiden, The Netherlands: TNO, 2020.

63 OMEGA-NET. COVID-19 and OMEGA-NET, 2020. Available: https:// omeganetcohorts.eu/resources/covid19-and-omega/

64 Lake ET. Development of the practice environment scale of the nursing work index. Res Nurs Health 2002;25:176-88.

65 Zangaro GA, Jones K. Practice environment scale of the nursing work index: a reliability generalization meta-analysis. West $J$ Nurs Res 2019;41:1658-84.

66 Braun V, Clarke V. Using thematic analysis in psychology. Qual Res Psychol 2006;3:77-101.

67 Morgantini LA, Naha U, Wang $\mathrm{H}$, et al. Factors contributing to healthcare professional burnout during the COVID-19 pandemic: a rapid turnaround global survey. medRxiv 2020. doi:10.1101/2020.05 17.20101915. [Epub ahead of print: 22 May 2020]. 